\title{
Developing Capacities for Inclusive Citizenship in Multicultural Societies: The Role of Deliberative Theory and Citizenship Education
}

\author{
Puja Kapai
}

Published online: 11 August 2012

(C) The Author(s) 2012. This article is published with open access at Springerlink.com

\begin{abstract}
Political frameworks such as assimilation, accommodation and multiculturalism that have sought to address difference have failed to achieve political equality and inclusion for immigrants, driven primarily by the flawed understanding of culture and identity in multicultural states. Offering a brief critique of these models, this essay advocates the use of deliberative theory in citizenship education as instrumental to building capacities for inclusive citizenship and cultivating belonging and inclusion in diverse societies. Deliberative practice enables the reconceptualization of citizenship as performative, involving responsibilities for dialogic engagement. Such capacities and responsibilities are indispensable for a just political order in multicultural societies.
\end{abstract}

Keywords Governance $\cdot$ Citizenship $\cdot$ Identity $\cdot$ Nation-states

\section{Introduction}

Although multiculturalism and the existence of diversity in societies is not a novel phenomenon, nation states around the world continue to struggle with difference. Events in recent history have resulted in an unprecedented proliferation of multination states, calling for a critical reconsideration of political frameworks and apparatus to account for the demographic implications of mass-scale immigration witnessed in the Twentieth Century (Castles 2003; Zlotnik 2001). Multicultural societies have long been working through different political arrangements with a view to locating the political 'other' within the framework of the liberal democratic nation state. These attempts have entailed the use of various models of inclusion of immigrants, ranging from assimilation and accommodation to the use of liberal multiculturalism and

Editor's Note: This article was required additional copy editing for English, but never received in time; hence its publication as was.

P. Kapai $(\bowtie)$

Center for Public Law Faculty, The University of Hong Kong, Pokfulam Road, Hong Kong, China

e-mail: puja@hku.hk 
multiculturalism as self-governance. Recent scholarship has revealed that each of these paradigms is undergirded by certain conceptions of culture and identity which, in the case of the former, fail to account for the fluidity of culture, and in the case of the latter, are based on a predominantly liberal understanding of one's identity and the relationship between the self and society (Spinner-Halev 1996). Insofar as these models for political inclusion remain grounded in discourse steeped in quintessentially liberal conceptions of culture, identity and the good life, they fail to account for variant conceptions of the good life and their impact on the construction of the self as an individual and the relational self as well as the role of culture and politics in facilitating equal access and means for the pursuit of life goals in a manner consonant with one's worldviews. The result is the exclusion of certain groups from substantive and meaningful citizenship in multicultural polities.

This essay interrogates some of the discourse on citizenship and traces the role of identity and culture in informing the modern conceptualization of the 'national identity'. In deconstructing the concepts of identity and culture, this essay illustrates that the characterization of both culture and identity as monolithic and static is fundamentally flawed in light of theories of identity-matrixing and the fluidity of culture, particularly given modern society's exposure to multiple cultural paradigms. It further argues that insofar as citizenship is predicated on an outdated understanding of these concepts, it will continue to render the modern immigrant a perpetual émigré regardless of their formal incorporation into the state's apparatus as a national or citizen.

This state of affairs is exacerbated by a number of features that are inherent to the liberal political framework. First, the nation-state model, which remains the predominant model for political organization, continues to extend rights and citizenship status based on traditional tests signaling connection or contribution to the nationstate, for example, birthplace, descent, loyalty, contribution to the community through residence and employment or national defense. Although an array of constitutional and human rights are extended to all persons present within the physical borders of the state by virtue of the territoriality principle, citizenship usually avails of an additional bundle of rights, typically, self-governance rights including the right to vote, be represented in office and to stand in elections. Upon acquiring citizenship or naturalizing as a national of the immigration country, the assumption is that the immigrant, now formally a national or citizen, has developed requisite attributes that render his or her ties to the nation sufficiently concrete, dependable and essentially, that he or she is now a part and parcel of the nation, subscribing fully to its ideological and political values and ethos.

The failure of the modern nation-state to effectively manage multicultural populations is attributable to this binary perception of identities as either rooted or uprooted, included or excluded, immigrant or national, passive and unengaged or active and engaged. The inability of national and political structures to account for the struggle invariably experienced by some immigrants as they negotiate multiple and sometimes, conflicting, aspects of their transitioning identities ends with those who are different being chalked out as the archetypical minority. This breeds the popular imagination and scripting of the immigrant as solitary, different, 'alien' and passive members of the polity, which characterization is then used to justify the treatment of immigrants as mere subjects of the political order rather than equal partners in the making of the social contract that is said to foreshadow the liberal democratic 
framework (Rawls 2001). The perceived lack of agency and capacity to contribute effectively to political discourse results in the distortion of their role in the political process and, indeed the misrepresentation of their interests and their true nature as a people as well as their capacities for political agency.

Second, democratic practice today is marred by groups of self-interested individuals who vote collectively to follow their own agendas and as such, the 'collective will' represents less the result of a reasoned, thought through position of the community, and rather more, a mere aggregation of different collective interests, resulting in the povertization of democratic outcomes. This, coupled with their general lack of political power and minority status, minority interests and rights are routinely politicized in public discourse, often resulting in negative verdict on issues affecting such interests. This has led to a crisis of governance that is obsessed with governance of the other,' rendering the rights of the groups concerned irrelevant, diluted or oppressed.

This state of affairs is driven by multiple factors. The lack of political and institutional mechanisms to facilitate the effective inclusion of immigrant nationals into the polity, the failure to recognize the role of identity politics and its invidious influence on the development of law and policy to the detriment of immigrant minorities, and the general lack of any efforts to develop a framework through which to cultivate a culture of civic responsibility and ethical engagement in the public sphere. Together, these circumstances have created an atmosphere of distrust and tainted the process of effective civic engagement to enable a responsible discourse and outcomes that are in the broader interests of the multicultural society as a whole.

In advocating a 'performative' vision of citizenship, this essay builds on the critique of the conceptualizations of identity and culture, arguing that the inherent properties of culture and identity as properly recognized offer unique opportunities for influencing the evolution of individual and group identities and their reception of values and norms in multicultural societies as they interact with societal structures and processes. This requires a reorientation of modern democratic practice towards deliberative practices, a direction where public reason is brought back to the drawing board as the primary justification for decisions and policies. Furthermore, access to this space for public deliberation is to be expanded to include all groups and individuals. There is a need to extend the role of minorities beyond 'subjects' and to reconstitute them as individuals and groups with a civic responsibility. Such a public deliberative sphere, in which public reason is to reign supreme, would serve to improve capacities for engaging the 'other', provide opportunities for cooperation, reduce distance between communities, enable the pursuit of common goals and reduce spheres of perceived and actual distance and ultimately, acclimatize the groups to extend their circle of trust to include other political actors. When seen to exercise their civic responsibilities in a manner that aligns with the common pursuit of the general good, particularly by drawing on the discourse of public reason, the qualities of loyalty, sense of peoplehood and belonging to a nation rooted in nationalism and that national education strives to achieve, will materialize through these practical experiences rather than remain mere theoretical aspirations or misguided notions of the need to demonize the other as part of one's display of allegiance to the nation.

Finally, this essay argues that national education needs to be reformed into citizenship education in order for this new political order to take hold and materialize. 
Whilst there are aspects of political practices that would require critical review and change, with a view to a longer-term development of a discourse society that is built on a firm foundation of values that characterize inclusion, good faith, virtuosity, reasoned deliberation and capacities for continuing and critical self-reflection. It is envisioned that this will help cultivate a culture of participatory democratic practice in which nonpartisan discussions can be had and reasoned deliberation can be applied to the democratic moment of decision-making. This type of civic engagement will inculcate strong bonds of membership, commonality of purpose and ultimately, trust. In time, this trust can be capitalized upon to serve achieve the most fundamental and difficult goals of justice, a substantively equal and inclusive society.

Part II of this essay examines the nature of political arrangements that have sought to present immigrants with a space for inclusion into the national framework, examining their capacities for impartiality and equal treatment towards individuals and groups yielding from backgrounds that are different when compared to the predominantly Anglo-Western, Judeo-Christian sensibilities that characterize the ethos of modern liberal democratic countries. It argues that the terms based on which the paradigms offer inclusion are inherently liberal in their ideological foundations. As such, they fail to offer meaningful integration to immigrant communities seeking long-term inclusion into society on equal terms because inclusion is conditioned on the acceptance of liberal ideological underpinnings that substantively represent prerequisites for the acquisition or realization of equal citizenship and argues that the net result is that modern liberal democratic framework singles out particular communities for exclusion.

Part III unpacks the notions of identity and culture, drawing on the critique of their current conceptualizations and liberal underpinnings presented in the preceding section. It argues that identity and culture are not static but rather, are in a state of constant flux as they interact with multiple social forces that alter them with each interaction, just as these social structures are themselves altered by this exchange. Building on this, the section highlights opportunities for engaging difference meaningfully in multicultural societies.

Part IV provides a brief overview of modern democratic practice in liberal democratic states and sets up a case for re-conceptualization of citizenship as 'performative'. It further emphasized the role of deliberative democratic practices in ensuring justice in political processes and their outcomes in multicultural societies. Part V introduces a framework for citizenship education that can serve the ends of a model of deliberative democracy. In Conclusion, Part VI by constituting citizens that are virtuous, exercise their democratic rights responsibly through reasoned civic engagement and who can contribute to the noble task of un-working the deleterious impact of past atrocities and historical prejudice that have marginalized immigrant communities.

\section{The political organization of multicultural societies and the politics of difference: accommodation, assimilation and integration}

The existing impasse on the calibration of difference in modern multicultural societies can be traced back to the models of governance employed by the governing 
regimes. Classic immigration countries have attempted to manage their diverse populations through various policies designed to ensure minimal disturbance to the foundational values and systems of the receiving community. Most have adopted models of assimilation and differential exclusion. Assimilation seeks to break down differences between immigrants and citizens by encouraging national language education and familiarization with cultural and social practices of the nation. Differential exclusion restricts the immigrants' ability to be incorporated into the society as settlers through its strict policies against long-term settlement by these groups. The primary aim of allowing immigrants into these countries was to benefit from their labor during the industrialization period (Castles 2003). It was only in the late 70s and early 80 s that these policies progressed towards more accommodative models in light of human rights developments. These held governments accountable for serious human rights violations. In recognition of the rights of ethnic communities, immigration countries have gradually transformed their policies to accommodate them, however, not without antagonizing public sentiment at home. This has led to the isolation and racialization of and discrimination against the "other". Despite this, ethnic communities developed strong intra-group structures to serve their needs and have continued to survive in their distinct neighborhoods and communities (Castles and Miller 1998).

Among democratic nations, models of political arrangements have ranged between those encompassing varying degrees of accommodation of ethnic groups' cultural and religious rights and practices to assimilationist models that seek to eliminate difference through encouraging compliance with and commitment to mainstream values, sometimes mandating this indirectly through citizenship policies and other requirements for naturalization. ${ }^{1}$ Very rarely do states allow internal self-governance, which has usually been reserved for groups that have been recognized as First Nations or indigenous to the land concerned. ${ }^{2}$

Accommodative models are more widely known as multicultural models take a variety of forms but generally, policies of multiculturalism recognize minority groups as having distinct attributes which find their just expression in their own language, culture, and social etiquette. Thus, multiculturalism recognizes the rights of communities to maintain their cultural, linguistic and social systems and to be protected equally against the intrusion of any of their constitutional rights in this regard. However, in most of its modern forms, multicultural policy is conditioned on the

\footnotetext{
${ }^{1}$ For example, the United Kingdom takes a liberal democratic approach, premising its decisions to accommodate or reject certain practices based on the foundational principles protected by a liberal constitution underpinned by principles of human rights and other constitutional rights. Canada, on the other hand, adopts the multicultural political model, allowing communities a wider space in which to practice certain aspects of their culture or religion. Ultimately, however, Canada too, is insistent on the requirement that practices comply with the demands of constitutional equality and human rights protections as provided for in the Canadian Charter of Human Rights and Fundamental Freedoms 1981. France, on the other hand, prohibits the public manifestation of religious affiliations and generally disallows special accommodation on grounds of religion.

${ }^{2}$ The First Peoples Nations of Canada, for example, enjoy such rights of self-governance. However, there continue to be struggles between the groups and the federal government in seeking to assert at least minimal authority over the groups' practices, particularly those involving the determination of rights of inheritance of First Nations status, marriage between individuals from the different Nations and inheritance, for example.
} 
requirement that minority group practices be in conformity with basic principles of equality and non-discrimination and obey the law. In essence, accommodation depends on compliance with liberal principles. This section identifies the broad framework of these models and offers a brief critique for some of their critical failings.

\section{Liberalism as a model for multicultural citizenship}

Liberalism as a theory of citizenship prioritizes autonomy and liberty, allowing the individuals to pursue their private interests without interference from the state. It is predicated on the idea that all individuals should be free to pursue their visions of a good life. The liberal democratic constitutional framework serves to ensure, at least in theory, that all people are afforded equal protection from government infringement of their liberties in their pursuit of this good life. In order to ensure that this protection is extended to all citizens, liberalism demands all public institutions to comply with the principles of equality and non-discrimination.

Liberalism's ideological framework thus offers terms of inclusion as long as they meet standards of equality. This is imperative to lend credibility and legitimacy to the justness of the liberal paradigm and its characterization as a framework that facilitates the pursuit of various versions of the good life. Therein however, lies liberalism's paradox insofar as it seeks to exclude from its framework the accommodation of groups that impose unequal terms on certain members in their groups (Coleman 1996). It has been argued therefore, that liberalism promotes certain visions of the good and as such, equality is conditioned on groups sharing liberal ideals (SpinnerHalev 1996). Accommodative practices have therefore suffered from the charge of ethnocentric biases given that liberal values are applied to adjudge the acceptability of practices for the purposes of multicultural accommodation. On these terms then, the liberal project has long been explained against the backdrop of a social contract.

The reason why liberalism apparently succeeds as a suitable framework for accommodation is that by safeguarding equal rights for all in the public sphere, liberalism relegates culture to the private realm, where people are free to practice their beliefs as they desire. By keeping these differences grounded in culture and religion firmly out of the public eye using this dichotomy between the public and private, liberalism privatizes culture although it can appear in public but subject to the principles of equality and non-discrimination. The privatization of difference gives the impression that the polity as a whole need not deal with cultural difference. However, as recent examples have revealed, the divide between public and private spheres is not clear-cut and governments have been challenged by acts manifested in private due to their strong implications in the public sphere. ${ }^{3}$ In light of the recent debunking of this artificial distinction and the recognition of the fluidity between public and private spheres has exacted a more discerning approach from the liberal framework. The challenge this has presented has left liberal governments scrambling

\footnotetext{
${ }^{3}$ For example, the implications for liberalism and its inability to deal with the challenge of difference effectively and on an equally across all groups has been most acutely felt in cases involving manifestation of religious beliefs at school and at work in the United Kingdom in the cases of $R$ (Begum) v. Governors of Denbigh High School [2006] UKHL 15 and Ahmed v. UK (1982) 4 EHRR 126.
} 
for a suitable alternative approach to the conceptualization of cultural and religious difference as systems that necessarily have a 'public' dimension.

Liberalism is particularly skeptical of affording any political or legal status to groups (Spinner-Halev 1996). Liberal theory affords protection to individuals on the assumption that all their interests can be adequately protected based on the recognition of their needs as individuals. However, the theory overlooks the role of individuals within the collective, ignoring the critical relational influence of group membership on the constitution of one's identity. Liberalism assumes that through the protection of individuals, their membership within a particular group is adequately secured. Thus, whilst liberalism protects individual rights, indirectly, it facilitates the suppression of group rights through its framework. The theory fails to appreciate the need for specific protection of group rights as an aspect of enabling the joint pursuit of common life goals of a group as a group, or the intricate relationship between the individual and the group they identify with. Indeed, a reading of Charles Taylor's Sources of the Self (Taylor 1992) against the liberal framework for the recognition of individual rights underscores the importance of recognizing the liberal values and presumptions underlying liberalism's characterizing of individuals, their relationships with the community and the government and their needs. This individual-centered conception of identity fails to capture the role of group membership in the constitution of identity. It further fails to address the dynamic between individual and group identity and its critical contribution to pursuing a life of meaning. Thus, as an accommodative theory, liberalism fails with respect to those groups for whom group identity and performative aspects of one's identity in the 'public' sphere require protection in order for their vision of the good life to be meaningfully recognized.

In light of the terms for inclusion presented by liberalism and the framework's inherent preference for liberal values and modes of organizing the self and community, minority groups whose worldviews do not comply or fit neatly within this frame are excluded from autonomous self-governance or the protection of their key constitutional rights that would enable them to pursue the good life. Moreover, working against a framework that is already pitted against groups and non-liberal values, minorities necessarily struggle without political power as they often lack the means and resources to adequately represent their interests in a political process that is skewed towards certain outcomes, both systemically and substantively given the force of majority voices. Although individually, they have rights, majoritarian politics prevents them from having the desired impact in terms of numbers without adequate counter-majoritarian or affirmative action measures in place.

Multiculturalism: accommodation through law or exceptions to the law?

On the other hand, some models of multiculturalism that afford group rights to minorities have resulted in the fragmentization of multicultural society, often concretizing boundaries between different ethnic groups. Majority ethnic groups become wary of the differential treatment afforded to newcomers, causing resentment towards them. Furthermore, the extension of autonomy to minority ethnic groups vis-à-vis their members results in the deregulation of activities that traditionally fall within the state's prerogative, for example, equality and non-discrimination. Such a separate 
system for the dispensation of justice and the protection of rights depletes the possibility of and the incentive for the development of a 'national' attachment to the host community, thereby further isolating minority groups from the national majority. This serves as a disincentive for any future engagement between minority and majority ethnic groups as they are seen as having polarized interests. The struggle for political recognition becomes one for wresting power from majority groups to divide among the different minority ethnic groups in society. There being no common agenda between the different groups, they generally tend not to work together. These circumstances can result in a critical lack of social cohesion and political deadlock across a range of issues.

Feminist scholars have also argued that group rights afforded under multicultural arrangements, lead to oppression of women and children whose rights may be at risk under regimes where the groups' or collective interest is prioritized over the needs and rights of individual members. This may result in the perpetuation of discrimination and patriarchal practices that are characterized as endemic within certain communities.

There are limitations to both approaches. The problem is not necessarily the framework but the fact that accommodative frameworks are generally unaccompanied by complementary features which serve to reduce difference or enhance intercultural exchanges. If anything, in their present forms, they serve to antagonize all groups in multicultural societies, pitting them against each other often leading to confrontational politics. Both paradigms entrench differences as a result of growing negativity, persistent 'othering' that is reinforced through policy-making processes and policies themselves, and the reinforcement of the historical power dynamic between the 'colonizer' and the 'colonized'. The complete lack of identification between different groups results from the tensions produced by the unequal political powers and particularly, the overwhelming power of the dominant group insofar as it is in a position to 'recognize' or 'tolerate' whilst the minority is subject to this domination through the expression of its political will.

Existing accommodative frameworks tend to break down existing attachments. Liberalism or versions of civic republicanism seek to assimilate and create uniform citizens through the imposition of a set of values whereas multicultural measures result in group exclusion or isolation. Both liberal and multicultural policies generally fail to recognize the intrinsic boundedness of culture to minorities' identity and 'cultural citizenship' as an essential component to their self-determination. Assimilation stifles cultural identification, particularly the community-expression dimension of it, whereas accommodation distorts it or suppresses it in its authentic form. Both are damaging and marginalize the communities concerned, rendering minorities outsiders to their own communities but also, in the mainstream society.

Multiculturalism has been criticized in recent years for its rigid focus on liberal values and its general disregard for the merits of empowerment through responsibility, reciprocity and mutuality as opposed to the rights-oriented model, which focuses on the dichotomy between the subject and the government as the protector of these rights. Multiculturalism based on liberal ideology has failed to include minorities through models of citizenship that enable the coexistence of cultural difference and belonging to the nation within a single individual. This calls for greater synchronicity between the recognition of cultural difference, civic equality and civic engagement 
rights and practice in plurinational states and a more sophisticated understanding of how identities are formed and maintained. At either extreme, both the liberal and multicultural paradigms run the risk of fragmentation of multicultural societies. However, if coupled with certain measures that seek to cultivate greater participation of minority groups within society, to reduce othering and the deleterious impact of certain policies, these frameworks would be better able to achieve the goal of a stable, just and inclusive society.

Brysk and Shafir have referred to the plight of minorities in such societies as the 'citizenship gap' (2004). The status of some individuals in societies where citizenship is primarily defined by birth, descent or blood and sometimes by residence, achievement or other identity, is such that they lack the usual bundle of rights that they would ordinarily have if globalization and its effects were adequately accounted for and understood. Although globalization brings with it new opportunities and forms of intercultural exchange, from a governance perspective, the opportunities merely provide certain 'access' rights but without the "membership or responsibility" that comes with citizenship (Brysk and Shafir 2004). Whilst some people find themselves in a state of dual citizenship, there are those whose citizenship status is ambiguous or second-class, for example, ethnic groups or tribal and rural inhabitants. These people fall through the 'citizenship gap' (Brysk and Shafir 2004).

The dynamic of globalization is intense and moving at a fast pace. This wave of cosmopolitanization has critical implications for the notion of 'state-citizenship', previously determined by a simple test of certain attributes. However, the new types of residents in a bordered, borderless world that globalization has given birth to, demand a reconceptualization of citizenship, one that includes them and protects their interests adequately. Brysk and Shafir aptly describe the challenge as one requiring a "balance between 'citizenship deficit' due to the contraction of political democracy, and 'citizenship surplus', created by new venues of political influence” (Brysk and Shafir 2004).

Whilst a new structure of unterritorialised supranational rights is coming into play, it does not comprehensively define, inform or attend to this new concept of citizenship in terms of membership, accountability or justice. As Soysal notes, we are in a space between 'postnational citizenship', an era in which the sovereign-statehood model of citizen rights is transitioning to a realm where (some) rights are conferred internationally. The state-centric model has not as yet been abandoned (Soysal 1995). However, Soysal's thesis that universal human rights are the projected replacement for citizenship rights has been rightly criticized by others, such as Joppke, who notes that the nation will still be indispensible to the integration of immigrants (1999). The relationship between the local and the international citizen needs to be critically explored to determine the duties and rights of the national, the overseas national, the immigrant or the citizen immigrant, and to assess the junctures at which these identities intersect and complement or override each other. Given the inadequacy of existing measures to nurture a healthy sense of national and cultural attachment, a better understanding of the construction of identity, cultural identifications and attachments is required.

\section{Re-examining identity and culture}

Recent scholarship in anthropology, political philosophy and psychology has made it increasingly clear that cultural and identity formation processes are not uniform 
across cultures or groups. Moreover, the formation of culture and the constitution of individual and group identity are complex processes that cannot be tracked back to any singular influences of 'culture' or national 'inheritance'. Rather, cultural traits and attachments develop sporadically based on one's exposure to different 'Symbolic Orders' (Kearney and Adachi forthcoming, 2012). In today's global age, the local has become a microcosm of the global. Singular symbolic orders are complemented by multiple symbolic orders, working simultaneously to influence the development of one's identity. These attachments cannot be broken down neatly into any single category pertaining to culture, ethnicity or nationality.

This scholarship needs to be studied in greater detail by political theorists and constitutional law scholars to question what it is about culture and identity that warrants protection and to unpack the components that inform the development of culture and its attendant processes. Furthermore, the broader questions concerning identity, its formation and its entanglement with concepts of culture require critical review in light of the proliferation of movement of goods, people, values and practices. Broadly, flawed assumptions about the homogeneity of culture often form the foundational premise for the recognition of group-based rights. The misguided emphases of existing policies on the homogeneity of culture and the uniformity of its expression inhere in both the liberal and multicultural paradigms and have resulted in the misrecognition of minorities, their identities, values and needs. A less than adequate understanding of these complex questions have distorted politics and dialogue about the representation of groups and individuals in political frameworks and the meaning of culture and identity relative to such frameworks.

This section attempts to unpack these concepts to highlight the importance of a thorough deconstruction of culture and identity and their role and impact on the possibilities for living a meaningful life. An improved understanding of the (flawed) underlying premises of their existing conceptualization would facilitate the development of a more suitable framework through which culture and identity can be more effectively recognized and protected.

Identity-matrixing: understanding the construction of modern identity

Recent literature has extensively documented the various influences on the construction of the "self" (Lacan 1998). Jacques Lacan has introduced the "conception of the mirror stage" as a novel representation of the process of the construction of the self, which, he claims challenges the understanding of the self as a derivative of one's cognitive perceptions (1998). Through this theory, Lacan has sought to establish that the human being's self-image undergoes a transformative period. The "mirror stage" consists of a phase of identification which "situates the agency of the ego, before its social determination, in a fictional direction" (Lacan 1998) Although this process is internal, the individual's environment and its social language are applied to this mirror self-image to transform it into the realm of culture and other social indicators to constitute a social-self, which contributes to that person's individuality. These social indicators are called the "Symbolic Order" (Lacan et al. 1998).

Kearney and Adachi have interpreted the Symbolic Order as a "set of cultural constructions that is matrixed into individuals; this Symbolic Order provides the content and structure from which identity is formulated; it imparts of the ideologies, 
realities, and beliefs that constitute thought and the discursive formations that govern it" (forthcoming 2012). However, invaluable as Lacan's contribution is to enhancing our understanding of the construction of human identity, it bears a notable gap given its lack of account of the transcultural societies in which identity formation occurs today (Kearney and Adachi forthcoming, 2012). The transcultural conditions today reveal the existence and interplay of multiple Symbolic Orders (Kearney and Adachi forthcoming, 2012). Each individual therefore, inhabits multiple Symbolic Orders unless they live in isolated cultural groupings whereby the lack of interaction with other Symbolic Orders makes this an unlikely possibility.

Kearney and Adachi propose a complex model of "identity-matrixing" which captures the process in which the construction of an individual's identity takes place across transcultural settings and within which people constitute their identities through exposure to the external influence of multiple Symbolic Orders (forthcoming 2012). This matrixing across the numerous strata, vertical and horizontal, offered within each Symbolic Order provides the basis for the formation of a unique and individual identity (Kearney and Adachi forthcoming, 2012). Thus, vertical matrixing describes cultural constructions transmitted within a closed societal set within a particular Symbolic Order whereas, horizontal matrixing accounts for the process whereby cultural constructions are transmitted across parallel societal sets representing different symbolic orders (Kearney and Adachi forthcoming, 2012). Viewed in this manner, human identity is the result of a complex process of transcultural interactions, aptly depicted by such matrixing processes which function across economic, social, religious, ethnic and other groupings, both horizontally and vertically. As identity-matrixing reveals, people transform as they interact with other cultural structures, giving them the option to embrace norms from other systems, resulting in a unique self-identity which is not exclusively grounded in any single culture or identity. As Nussbaum notes, individuals have the capabilities to develop multiple identities, grounding their attachment to their cultural and national value-systems as well as to "the worldwide community of human beings" (Nussbaum 1996).

The key, therefore, must be to recognize the role of culture in the development of identities and to facilitate cultural learning by protecting interactive and developmental learning in the community or 'in-group' context. This is very different from protection of an abstract or intangible 'body of ideas' loosely defined as 'culture', the attributes of which can rarely be defined accurately or identified as a complete body of specific values. It is more accurate to describe the object of such protections as 'processes that nurture cultural development and enable human flourishing.'

Tapping into the dynamism of identity-matrixing: understanding its potential for reorganizing political engagement

As the foregoing analysis illustrates, to conceive of culture and identity as fixed concepts that are frozen and incapable of being influenced or evolving as they interact with other stimuli, is an oversimplified understanding of communities, peoples and multicultural societies today. Various forces combine in societies today presenting a unique experience of identity-construction to all individuals and groups, particularly in multicultural societies. To strive for a commitment to inclusion of those representing minority cultures or worldviews within both, mainstream and minority 
communities, the state must acknowledge difference and its complex manifestations that are neither monolithic in nature, nor static. Noting the dynamic processes and influences that impact the formation of identity and attachment to culture, the state must strive to implement structurally inclusive mechanisms that provide equal opportunities to enable positive and meaningful interaction with and to give expression to different cultural paradigms within the national culture. These mechanisms would more accurately reflect the interactive dialectic between national and local cultures, their interconnections and their invariable impact on each other.

Crucially, a better understanding of the formation of identities and the role of culture, national origin and other attributes in this process would enable the polity to be organized to accurately reflect the realities of citizens' identities. Recognizing the inherent fluidity of what one might refer to as our 'peripheral identities', and the influences we are susceptible to as we interact with others individually and as groups, there is hope that the fixed boundaries between 'us' and 'them' will begin to blur as groups come to a consensus on different issues and recognize a commitment to common ideals. This is provided that the necessary political structures to facilitate meaningful interaction are put into place and a civic ethos of responsible and virtuous citizenship is cultivated to make the most of such interactions. All of this has significant implications for citizen participation, inter-group dialogue and ultimately, the cultivation of 'national' belonging. Ultimately, a movement in this direction can help depoliticize the political arena and enable public discourse to be used more fruitfully to arrive at deliberated decisions that reflect the collective will in its true sense.

In light of this dynamic infiltration of cultural value systems crossing each other, the political process firstly, needs to reconsider and account for its implicit registration of difference based on cultural, religious or other differential identity-marker that dilutes the expression of the voter's will relative to that of the majority. Second, there is a critical need to address the citizenship 'gap' that results from liberal and multicultural policies in their current expressions. Third, in fully recognizing the dynamism of the process through which identity and cultural attachments are formed, multicultural societies need to establish mechanisms that positively influence this process of identity-construction so as to yield sentiments that reflect national as well as cultural attachments and minimize the marginalization of minorities. This can only be achieved through a structured, long-term reform of educational curricula to include democratic citizenship education directed at the cultivation of strong civic values including recognition, reciprocity, equality and the use of reason in public discourse. Fourth, these processes can positively impact the development of inter-cultural loyalties and allegiance such as the kind most critically required in multi-nation society.

\section{Interrogation modern democratic practices}

Outdated approaches to characterizing modern identity and the nature of citizenship today have resulted in the exclusion of immigrants and ethnic minorities from meaningful participation in the society. They are sometimes incorporated into the state's political framework when they fulfill stringent conditions imposing an alien value system on them. Despite formal inclusion, these groups find it difficult to participate in practice for a number of reasons, including the lack of a suitable space 
for reasoned discourse to communicate their interests effectively, feelings of dislocation, discrimination or the fear of reprisal or exclusion. This results in their marginalization in participatory governance and the development of relevant law and policy.

The entrenchment of practices and frameworks of exclusion is the subject of a contentious critique in political theory and theories of justice. Having briefly critiqued some of the existing paradigms of political governance of difference, it is important to correct perceptions of indifference, passivity and lack of capacity often attributed to the minorities and to locate the source of the problem.

Numerous theorists have criticized modern democratic systems for their lack of depth and engagement of the masses in the pre-decision-making moments. Democratic moments in many countries today represent a mere aggregation of the group's collective interests, as opposed to a deliberated account of their political will. In multicultural societies, democracy appears to be operating at its weakest. Liberal values and practices have long been championed as engendering in the public the desire to participate in decision-making through discussion of contentious issues of legal, social and political consequence and the liberal framework provides the space to do so. Through engagement in the public sphere, the market place of ideas enables the best ideas to come to the fore. However, as modern critics of the marketdominated paradigm have lamented, the system is subject to manipulation and domination by the most powerful voices. Likewise, political discussions are often dominated by mainstream voices due to inequalities of power.

Democratic practices reinforce the majority group's stronghold in politics, enabling them to steer the course of policy, oftentimes, to the detriment of minority interests. This has called into question the effectiveness of democratic mechanisms employed in determining the political will. Counter-majoritarian mechanisms remain weak as constitutional courts designed to safeguard minority interests reflect a strong commitment to the national public interest, political stability and with a view to avoid getting embroiled in judgments that bear serious political consequences. More importantly, however, they shy away from overstepping their constitutionally prescribed roles as interpreters of the law as opposed to engaging in policy-making from the bench. In cases involving conflicts between liberal values and cultural and religious beliefs or practices, judges apply the liberal constitutional framework usually prioritizing the twin values of equality and non-discrimination, which remain sacrosanct. ${ }^{4}$

Additionally, current democratic practice reveals that the mechanisms traditionally used for debate and engagement have lapsed into the monotony of 'routine' votecasting which decision is taken by individuals after a short period of self-reflection (if at all), rather than after vigorous debate and engagement with civil society institutions. Politics, thus, is marred by the decisions made by groups of self-interested

\footnotetext{
${ }^{4}$ This leaves the position of the minority particularly precarious in multicultural societies. Although there are decisions that reflect that judges do consider minority positions, in the majority of cases still, the reasoning reflects a failure to fully consider all dimensions of the impact of a decision or a position on the minority group concerned. This is usually the result of inherent limitations of the adversarial process which leaves it to the parties to define the pleadings and thereby, the issues at trial. This constrains judges in how they approach the issues in during their determinations. Furthermore, dealing with complex issues of this nature through courts inevitably means that the developments in law will be piecemeal since resources are finite and judges have to make economic use of these resources.
} 
individuals who vote collectively to follow their own agendas. It appears that nationalistic sentiments that may at one time have been the motivation behind thinking and acting in pursuit of the common good has increasingly been replaced by self-interested decision-making, fueled by consumerism, isolation from community-contexts and a general culture of making pragmatic decisions based on economic or materialistic considerations rather than ethical or moral reasoning informed by the duties that come with the privilege of enfranchisement. The process of voting and campaigning has been taken over by propaganda and materialism, which attract or split voters on issue-specific bases rather than a complete platform for the overall improvement of the community. As such, it has been argued that modern societies suffer from a democratic deficit (Fishkin 2009, 2010).

These circumstances beckon a reconfiguration of political institutions. It is suggested that by prefacing the democratic moment with a series of dialogic and deliberative processes, this 'democratic deficit' can be addressed. This would enrich the quality of political discussion and allow deliberation on the basis of the actual issues as opposed to allowing the discussion to be dominated by identity politics. However, to achieve this, the deliberative setting and actors need to be prepared for the exercise, which is no small task. This involves recourse to a virtuous ethics of citizenship and political participation: one that is inclusive and cultivates the values of substantive equality, autonomy and responsibility towards other members of the polity.

\section{Citizenship re-conceptualized: the promise of deliberative theory in promoting reasoned discourse and cultivating loyalties}

The state-centric vision of government has been viewed as an institution resulting from a set of independent administrative processes which lead to decisions that legitimize state action. However, a more citizen-centered vision of governance can serve to enhance the democratic legitimacy of decisions, particularly those regarding conflicting norms, thereby providing a more effective model for governance in multicultural communities. The concept of citizenship as membership needs to be revisited to account for the realities of the borderless world, in which political units do not necessarily congregate territorially. Moreover, the role of minorities needs to be extended beyond 'subjects' and reconstituted as political actors with civic responsibility. Given the fundamental role of memory in the construction of identities, a political process premised upon inclusive governance will create new memories and cultivate belonging in the larger community.

A revised conceptualization of citizenship as political agency is more appropriate in light of the fluidity of contemporary transcultural identities. Developing an institutional framework that supports citizenship as political agency rather than membership based on fixed attributes and a deliberative political framework can better effectuate inclusive political participation and create new spaces for belonging. A deliberative process that is substantively inclusive can shed light on the bases of difference and a political space within a rational discussion can ensue. It would also promote a culture for civic action through the recognition of the input of multiple groups and the principle of reciprocity and public reason to undergird meaningful and substantive participation. 
The challenge is to find a value system which resonates with these complex individuals in light of their multiple memberships so that it mobilizes feelings of belonging and responsibility towards a particular nation-state and invests them in its success. This requires the denationalization of citizenship and grounding belonging in political process and participation rather than physical or cultural signifiers of identity (Aleinikoff and Klusmeyer 2001; Aleinikoff and Klyusmeyer 2000, 2002), thus reconstituting citizenship as 'performative' as opposed to merely, status-bearing.

It is argued that deliberative theory is a framework that provides an integrated response to the challenge of modern citizenship in multicultural societies. As discussed earlier, democratic moments today represent a mere aggregation of the society's collective interests. Without a process to guide preference-formation, citizens often cast votes on misguided bases without understanding electoral platforms or the consequences of certain policies. Deliberative democracy provides an organizational context for meaningful dialogue between stakeholders, producing outcomes that have benefited from public reasoning and discussion among equals. The framework is premised on an exchange of public reasons and justification, which serve to legitimize the outcomes of the deliberative process (Kahane et al. 2010). The emphasis on public reason means participants must refrain from referring to contested conceptions of the good life in order to increase the likelihood of persuading others of their reason. It provides an opportunity for dialogue, engagement and to persuade others of their position with the confidence that their voices will be heard based on the principle of reciprocity, which is a critical element of deliberative processes (Gutmann and Thompson 1996).

This interactive deliberative space can also help negate exclusion, and ultimately minimize areas of conflict. It can foster critical reflection across cultures to root out stagnant practices and beliefs that are no longer held. This reflexivity should be fostered across all groups and is a healthy quality for value systems of various orientations. The deliberative democratic model can help build solidarity through these opportunities and at the same time, serve as a venue where the act of participation can and community engagement cultivates feelings of belonging and attachment across cultural groups to produce an inclusive polity, forging new collective and individual identities through exposure to multiple value systems. These identities will primarily be grounded in the commitment to civic engagement, harnessing the performative aspiration of modern citizenship. Inclusion and interaction in the public sphere will ultimately develop and deepen inter-cultural trust and understanding.

Whilst the democratization of the political setting may be a progressive step, it is meaningless if equality of access to democratic dialogue is granted in 'form' but not substance. For a system to be representative in fact, it must be undergirded by a systematic search for different voices that ought to be represented. This is essential if deliberation is to yield a meaningful outcome based on an accurate depiction of the different positions as opposed to 'surrogate' representation based on false assumptions about shared belief systems. This can be achieved through nominations or elections within different sub-groups. This will help ensure substantive participation.

The difficulty is the uncertainty that surrounds the reasoning process, if any, which leads to support for a particular decision. Outcomes are perceived as just when they can be directly correlated with reasoned judgment, thereby making them widely acceptable. Decisions which rest on reason are viewed as legitimate given the positive 
relationship implied between reason and justice. Conversely, outcomes lose their independent validity when they are perceived as stemming purely from sentiments of loyalty. In these cases, decisions are viewed as tainted by the bias that accompanies the support of members who allow group membership, identity or other common cause to influence their decision. It is difficult to trace decisions back to a particular line of reasoning as opposed to the sentiment of loyalty or prejudice, factors that often accompany decision-making generally.

Moreover, deliberative processes cannot be successful if the very basic source of some peoples' worldviews is excluded from the repository from which they make sense of their lives. A basic condition for trust requires complete openness to all reasons proffered in the process of deliberation if genuine understanding is to be cultivated between divided communities. Thus, the claim by deliberative democrats that only reasons that are acceptable to the 'general population' may be advanced as acceptable reasons for particular positions does not satisfy this requirement. There must be some leeway to allow arguments to materialize for a meaningful exchange to occur and determine the scope of disagreement.

Habermas requires that norms be validated independently of sentiment, i.e. that they should rely on reason (Habermas 1996). Rawls, on the other hand, requires a constructivist approach towards the universal through a law of peoples which reaches out to all groups and communities (Rawls 1999). ${ }^{5}$ For Rawls, what is reasonable it different from what is rational (means-end rationality). Rawls often also invokes 'practical reason' as represented by an independent human faculty, free from subjective influences to help achieve the Habermasian task of discerning a 'transcultural moral validity.' This universality of morals commands legitimacy. But is this what Rawls means? Rorty thinks he is actually referring to actual principles and conceptions as in fact arrived at in the course of creating a community (Rorty 1997). Therefore, practical reason is a process - rather than substance of agreement about universal norms. However, it remains to be questioned whether indeed, Rawls and Habermas share similar objectives. Rorty claims they are similar, particularly in light of their endorsement of Thomas Scanlon's answer to the "fundamental question why anyone should care about morality at all," namely that "we have a basic desire to be able to justify our actions to others on grounds that they could not reasonably rejectreasonably, that is, given the desire to find principles that others similarly motivated could not reasonably reject" (Rawls 1996; Rorty 1997). The ultimate goal is to appeal to ideas that others similarly appeal to so as to be able to justify the action suggested. Rorty has examined this relationship between justice and loyalty as explanations for particular judgments, questioning whether the notion of loyalty should be expanded to include a larger group of people so as to render it equivalent to an acceptable concept of justice (Rorty 1997). Through regularity in the exercise of finding or discovering overlapping interests and beliefs, there are prospects for enlarging the circle of loyalty.

Thus, the aim is to provide reasons for embracing a larger group into your circle of loyalty for the same reasons that underscore your current sphere of loyalty. In Walzer's terms, this would mean creating alternative 'moral identities' (Walzer 1994). Rorty's suggestion is that by drawing on these ideas, one can make a case

$\overline{5}$ This alludes to Rawls' 'overlapping consensus' theory. 
for interest-based appeal rather than belief-based appeal (Rorty 1997). This helps eliminate controversies about cultural or religious practices or minority rights. This view accords with Michael Walzer's notion that morality is inherently thick, intermingled with cultural beliefs and systems. 'Thin' principles can only be derived in special circumstances where the occasion calls for it in particular cases (Walzer 1994).

Although this approach is commendable, it does not cater to or account for those groups whose exercise of rationality or reason is derived from cultural or religious constructs and beliefs. There is however, promise to his proposal on how the creation of alternative moral identities can be facilitated. Rorty presents rationality and the acquisition of loyalty as part of the same activity (1997). He hints at how the circle of loyalty can be expanded by producing unforced agreements between different groups. This will assist in the dissolution of 'otherness' through processes which reveal the 'other' as reasonable or trustworthy people. He argues for the need to view reason not as a source of authority (as Kant or Plato would), but rather, as a process of facilitating agreement by persuasion. As time goes on, a continuum is produced along which, there are varying degrees of consonance between beliefs and interests. As these instances of overlap increase, there is increasing compromise, deference and trust. Gradually, these sentiments find expression through the development of loyalty towards a group (Rorty 1997).

Rorty surmises that moral identity therefore, boils down to the groups with which one identifies (1997). A common identity compels loyalty which undergirds moral behaviour that would befit a group member. This concept of identity is a 'shifting' concept which takes on a form depending on the associations we feel bound by or answerable to. Similarly, our moral compass is tugged in different directions depending on these affiliations. Walzer explains this with reference to our level of knowledge about the people we deal with. We have a thicker account of those we are familiar with and therefore, are on certain ground when we need to apply a moral analysis to decide how they are to be treated. It is all part of the shared system of knowledge which makes our actions understandable (therefore moral) to them. Once we distance ourselves from in-group members and need to decide how out-group members are to be treated, we rely on systems of 'law' to dictate the appropriateness of our actions because we only have a 'thin' conception of them (Rorty 1997). On this account, there is no 'core' or 'basic' self that espouses universal values by virtue of our human identity or principles derived purely from 'reason' and therefore prior to our 'subjective' loyalties. ${ }^{6}$ If this is an accurate depiction of the human identity, then we must accept the plurality of identities and incorporate their fluidity into our decisionmaking processes.

This alone, however, would not guarantee the exercise of one's civic duties to participate in democratic decision-making. A further dimension to responsible and participatory citizenship pertains to the influences on the decision-making process itself. A critical element in developing trust within diverse communities is the transparency of the decision-making process and the underlying positions adopted by different parties in arriving at those decisions. Whether those positions are

\footnotetext{
${ }^{6}$ Clearly, this account is non-Kantian in the sense that it seeks to premise morality on grounds other than the capacity for human reasoning, which Kant believed governed moral imperatives.
} 
informed by reason, morality, pragmatism or prejudice, self-interest and power will strongly affect the development of trust within multicultural societies. Therefore, Gutmann approaches the question of cultivating civic responsibility from the perspective that the primary ingredient must necessarily be the cultivation of a moral commitment to justice, rather than to any community (2002).

According to Gutmann, "Doing what is right cannot be reduced to loyalty to, or identification with, any existing group of human beings" (p. 69). The capacity to determine the morally right decision will necessarily result in upholding the fundamental guarantees of equality and non-discrimination. Whilst this position is undoubtedly ideal, it can only be achieved progressively, rather than all at once. Initially, relying on reason, pragmatism and trust, processes designed to tap into public opinion will solicit public opinion through fair systems that provide for equality of access and opportunity. Justice follows as part of the 'justice as fairness' approach but is complemented by the trust that has been built through a reason-based discussion that breeds affiliation and commitment through the appeal of reason and trust rather than 'loyalty' grounded in nationalism or race or other attributes external to the processes of political participation. Gutmann, however, ignores the inevitable influence of identity on feelings and the effect of sentimentality on capacities for reasoning (at a subconscious level) as well as loyalty to reason over emotion.

As Sunstein notes, depending on the particular conceptions of justice and democracy one adopts, a polity may be required to make a choice as to its overriding priority between justice and democracy. On this view, if justice is to be prioritized, then democracy would need to be accordingly limited. On the other hand, if democracy is to be prioritized, then this may mean compromising certain principles of justice. However, there are also ways in which the two can be mutually reinforcing (1997).

One understanding of democracy is that it entails a deliberative exercise whereby preference-formation is facilitated through deliberation and reasoned discussion. In this institutional arrangement, the outcomes which result are considered 'just' as a result of the reason-based process through which preferences formed, critiqued and reformed. Through a representative system of politics where decision-makers are held accountable to the deliberative voice and its reason, this deliberative version of democracy responds to the criticisms of democracy as adopted in its pure form as a system of one-man-one-vote without accounting for the role and value of reason or the space and tools required for preference formation and its facilitation and complements these two versions to render a more effective democracy in the true sense of the word (Sunstein 1997).

The question often asked is whether there is a conflict between the appeal to interest as opposed to appeal to reason in arriving at agreements. Reason can be influenced by both, reason and interest. One view of justice relies on reason. The other derives legitimacy through the utilization of just processes which assume the outcome produced to bear the hallmarks of justice (Rawls' 'justice as fairness' approach). Thus, one may begin with an 'interest-based' appeal to expand the circle of loyalty. Once numbers have accumulated, the system can then progress towards procedural fairness and ultimately, to reason-based justice, seeking a more perfect and just society.

Given the challenges that accompany deliberation in multicultural settings, it is pertinent to recognize the impossibility of agreement on meta-issues at the outset and 
to begin the trust-building, loyalty-enlarging process with simpler questions that need addressing. One possible approach is to adopt Sunstein's view. Forced attempts at complete agreement over high-level theory about basic questions would only increase tensions and affirm the skepticism of parties belonging to different groups that no consensus is indeed possible between them across the board. He posits that seeking agreement over the complete theorization of questions which are so heavily contested (both, in intra- and inter-group settings) is unnecessary and undesirable (Sunstein 1997). This is primarily because identity politics have often dominated the process of any genuine agreement being reached between different interest groups. A classic strategy deployed by numerous political 'camps' to further divide groups and usurp the function of any targeted deliberation geared towards reaching a compromise or agreement has been to link other contentious questions that lie on the peripheral boundaries of the issue being considered. This conflation of political issues distorts the political process, heightens inter-group tensions and confirms group polarization theories (Fishkin 2009), rendering it less likely that groups would see their interests converging. This jeopardizes any prospects of a meaningful dialogue or the enlargement of the 'circle of loyalty'. The atmosphere for effective deliberation is purged due to continued distrust.

Whilst various studies have revealed that deliberation, even in informal or limitedquestion contexts, have an immense empowering and emancipatory effect on those who partake in the process, social inequalities have long been known to affect political inclusion due to a lack of civic education. These capacities need to be built across different groups in order to defeat the social inequalities that render certain groups least likely to be included in political participation despite inclusive measures. This implicates a unique and significant role for citizenship education.

\section{Citizenship education: cultivating capacities for deliberation}

In order for this vision of enlightened deliberative engagement that is inter-cultural and intra-cultural to materialize, apart from the institutional reforms that are required at the political level, there is a critical need to re-examine the values that we nurture at schools. One only has to consider the deep-rooted nature of inequalities, discrimination and prejudice within our communities to imagine the leap forward that is required if we are to prepare our children to be effective in negotiating the value pluralism that increasingly pervades the communities that we live in today. The characteristics that need to be fostered to instill in the leaders of tomorrow the virtues of reflexivity and reciprocity and the ability to draw a distinction between reason and emotion or interest (Kahane, et al. 2010).

Although numerous schools introduce students to some form of civic education, students invariably receive lessons in national history and citizen values that are deeply entwined with nationalism and selectively highlight events of national pride. Oftentimes, the curriculum is designed to present an image of the nation that is glorious, representative of noble values and beliefs, its peoples as homogenous and as having traits that are characteristic of their national culture. The stories that are told of national heroes usually present a demonized enemy over whom their peoples, were righteously victorious. The books and materials used are usually similarly oriented, 
presenting images that portray a homogenous group of being who descend from this proud historical national heritage and as such are rooted in the land. These illustrations tend to present a skewed perspective on what is, in fact, the myth of the 'nation state' and in today's day, represent a figment of the 'national imagination' that is routinely drawn on by politicians, educators, parents and others in positions of power, to indoctrinate a young nation into commitment to a culture, an ethos and most importantly, to a peoples who are presented as singularly having an a priori right to the territorial boundaries within which their nation has claimed statehood.

Necessarily, in a multicultural society, immigrant children, be they first, second or third generation immigrants, fail to see themselves in this national imaginary. Likewise, other children fail to see them as part of their national reality. Therein are sowed the seeds of exclusion, the justification for differential treatment and the legitimacy of distinctive treatment. In order to ensure that we help cultivate values that will lend future citizens naturally to the kind of behavior that is desirable and conducive to effective deliberation in a plural society, children need to receive citizenship education that is firmly committed to an agenda to impart a range of values. These should include, firstly, an understanding that any position requires justification that is based on reason. Second, they must respect the process of deliberative decision-making primarily by respecting the value of the public exchange of reasons. Third, any exercise entailing reasoned engagement with others requires that the principle of reciprocity be adhered to whereby they are taught the importance and morality of maintaining an open mind in considering the force of reasons offered by viewpoints that differ from their own (Kahane, et al. 2010). Fourth, they must recognize that at times, their reasons may not be treated as persuasive of a position and in those circumstances, their argument, being the weaker of the few may result in a detrimental impact on their self-interest. Fifth, they must learn to distance the impact of the negative outcomes that are inevitable in the course of such processes from time to time, and their moral duty to continue to engage in and contribute to the political process despite the fact that such occurrences may recur. Sixth, where such an outcome has resulted, they must consider the underlying reasons for it. Engaging in self-reflexive exercise through a perspective that is temporarily detached from their self-interest should be inculcated as a desirous and virtuous endeavor insofar as it is aimed at gaining a better understanding of the distance between the public reason and their private reason. Finally, they must recognize the morality of a continual critique of past decisions and the reasons proffered with a view to the possibility of arriving at even better decisions undergirded by strong reasons for change. This builds in the reflexivity across decisions and time, fostering a process that is continually enriched through its inward gaze.

\section{Conclusion}

A systemized process which serves to inculcate values that mobilize citizens into civically responsible citizens would greatly enhance the overall quality of democratic decision-making and issue-resolution in multicultural societies. The quality assurance comes from the fact that individual and group interests from various backgrounds will be better understood in light of an education that has served to enhance such understanding between different communities. 
Such 'home-grown' processes of inclusion, belonging and dialogue are critical in generating commitment towards a multicultural polity and encourage the exercise of civic responsibilities. They also positively influence identity-construction, feelings of belonging and attachment. Substantive deliberation through these means could well serve as the beginning of a slow but long-term process of inclusion and belonging. The sooner this sense of civic and virtuous responsibility is cultivated and tapped into, the more adept the members become at engaging in a process of collective deliberation. Interactions between groups that are mediated through public reason to produce collective agreements may be the first step in the long journey towards building the social conditions needed to accompany constitutional and legal change. We need social forces, processes and a citizenry committed to performing its duties to accompany constitutional and political processes rather than have blind faith in the constitution or judges to achieve justice.

Through citizenship education that focuses on the development of capacities for the virtuous exercise of one's civic responsibilities, it is possible to enhance understanding and forge loyalties across cultures by appealing to the strength of unity in diversity. Such a reconstituted political dynamic incorporating civic responsibility and deliberative access would go a long way towards complementing existing theories of justice and building on their framework to foreshadow an inclusive multicultural society.

Acknowledgements Assistant Professor, Deputy Director, Centre for Comparative and Public Law, Director, Summer Social Justice Internship, Co-Convener, Diversity Studies Emerging Strategic Research Theme, Faculty of Law, the University of Hong Kong. Research for this article was supported by the University of Hong Kong's Small Project Grant entitled, 'Deconstructing Citizenship and Cultivating Belonging: Practice in Multicultural Societies,' which entailed an empirical study of the workings of deliberative democratic practice in Hong Kong. An earlier version of this paper was presented at the International Conference on Governance and citizenship in Asia: Paradigms and Practices, 18-19 March 2011. The Conference was organized by the Centre for Governance and Citizenship at the Hong Kong Institute of Education. The author would like to thank the participants at the Conference and an anonymous referee for their insightful comments on the presentation and an earlier draft of the paper and also, Katrina Chik, Sarah Chiu, Karen Choi, Harriet Chu, Claire Hussin, Stephanie Lam, Senia Ng, Yvonne Ngai, Leticia Tang, Lily Yip and Christine Yu for their excellent research support.

Open Access This article is distributed under the terms of the Creative Commons Attribution License which permits any use, distribution, and reproduction in any medium, provided the original author(s) and the source are credited.

\section{References}

Aleinikoff, T. A., \& Klusmeyer, D. (Eds.). (2001). Citizenship Today: Global Perspectives and Practices. Washington DC: Carnegie Endowment for International Peace.

Aleinikoff, T. A., \& Klyusmeyer, D. (Eds.). (2000). From migrants to citizens: Membership in a changing world. Washington: Carnegie Endowment for International Peace.

Aleinikoff, T. A., \& Klyusmeyer, D. (Eds.). (2002). Citizenship policies for an age of migration. Washington: Carnegie Endowment for International Peace.

Brysk, A., \& Shafir, G. (2004). Introduction. In A. Brysk \& G. Shafir (Eds.), People out of place: Globalization, human rights and the citizenship gap (pp. 3-9). New York: Routledge.

Castles, S. (2003). Migration, citizenship, and education. In J. A. Banks (Ed.), Diversity and citizenship education: Global perspectives (pp. 17-18). San Francisco: Jossey-Bass.

Castles, S., \& Miller, M. J. (1998). The age of migration: International population movements in the modern world (2nd ed.). London: Macmillan. 
Coleman, D. L. (1996). Individualising justice through multiculturalism: the Liberal's dilemma. Columbia Law Review, 96(5), 1093-1067.

Fishkin, J. S. (2009). When the people speak: Deliberative democracy and public consultation. New York: Oxford University Press.

Fishkin, J. S. (2010). Response to critics of when the people speak: the deliberative deficit and what to do about it. The Good Society, 19(1).

Gutmann, A. (2002). Democratic citizenship. In J. Cohen (Ed.), For love of country? (pp. 66-71). Boston: Beacon.

Gutmann, A., \& Thompson, D. (1996). Democracy and disagreement. Cambridge: Harvard University Press.

Habermas, J. (1996). Between facts and norms: Contributions to a discourse theory of law and democracy. Cambridge: MIT.

Joppke, C. (1999). Immigration and the Nation State: The United States, Germany, and Great Britain. New York: Oxford University Press.

Kahane, D., Weinstock, D., Leydet, D., \& Williams, M. (Eds.). (2010). Deliberatve democracy in practice. Vancouver: UBC

Kearney, M., \& Adachi, S. (forthcoming, 2012). Mapping hybrid identities: A matrixing model for transculturality. In: Kearney M (Ed.), From conflict to recognition: Moving multiculturalism forward. Oxford: Rodopi Press.

Lacan, J. (1998). The mirror stage as formative of the function of the I as revealed in psychoanalytic experience. In J. Rivkin \& M. Ryan (Eds.), Literary theory: An anthology. Oxford: Blackwell.

Lacan, J., Miller, J.-A., \& Sheridan, A. (Eds.). (1998). The four fundamental concepts of psycho-analysis (W. W. Norton \& Company Ltd, London 1998) 279. London: W. W. Norton \& Company Ltd.

Nussbaum, M. (1996). Patriotism and Cosmopolitanism. In J. Cohen (Ed.), For love of country? (pp. 2-20). Boston: Beacon.

Rawls, J. (1996). Political liberalism. New York: Columbia University Press.

Rawls, J. (1999). The idea of public reason revisited. Cambridge: Harvard University Press.

Rawls, J. (2001). Justice as fairness: A restatement. Cambridge: Harvard University Press.

Rorty, R. (1997). Justice as a larger loyalty. In R. Bontekoe \& M. Stepaniants (Eds.), Justice and democracy: Cross-cultural perspectives (pp. 9-22). Hawaii: University of Hawaii Press.

Soysal, Y. N. (1995). The limits of citizenship: Migrants and postnational membership in Europe. Chicago: Chicago University Press.

Spinner-Halev, J. (1996). The boundaries of citizenship: Race, ethnicity, and nationality in the liberal state. Baltimore: John Hopkins University Press.

Sunstein, C. (1997). Deliberation, democracy, disagreement. In R. Bontekoe \& M. Stepaniants (Eds.), Justice and democracy: Cross-cultural perspectives (p. 93). Honolulu: University of Hawaii Press.

Taylor, C. (1992). Sources of the self. Cambridge University Press.

Walzer, M. (1994). Thick and thin: Moral argument at home and abroad. Notre Dame: University of Notre Dame Press.

Zlotnik, H. (2001). Past trends in international migration and their implications for future prospects. In M. A. B. Siddique (Ed.), International migration into the 21st century: Essays in honour of Reginald Appleyard (pp. 227-261). Boston: Edward Elgar. 